The surgeon's personal attention to his patient and careful explanation of surgical procedures reduce apprehensions and aid recovery.

\title{
Psychological Preparation for Surgery
}

\author{
ChARLES S. BRANT, Ph.D., HeRbert VOlK, M.D., Med.Sc.D., and BeRNARD KUTNER, Ph.D.
}

$\mathbf{N}$ EARLY all practicing surgeons would agree in principle that a total-care approach to the management of patients undergoing surgery should include careful psychological preparation. But such preparation for emotional and social problems resulting from hospitalization, surgery, convalescence, and rehabilitation is not always regarded as essential to comprehensive medicine, even though the literature attests to its importance. Kaufman (1) writing of the patient's need for emotional support, states :

"The patient must be emotionally prepared to accept necessary surgery without undue anxiety and fear. Everything must be directed toward reducing the psychological stress and trauma of anesthesia and surgery to a minimum. The patient must receive the emotional support he needs and deserves during the immediate postoperative periods. . . A properly utilized half hour or hour of psychological preparation may give the patient sufficient emotional security to obviate preventable psychosomatic complications. Furthermore, it seems to me that such

Dr. Brant is assistant professor of anthropology and sociology, Portland State College, Portland, Oreg., and was formerly research associate in surgery at the Albert Einstein College of Medicine. Dr. Volk is assistant professor of surgery, and Dr. Kutner is assistant professor of preventive and environmental medicine at the Albert Einstein College. Their research was supported by the Russell Sage Foundation and by a grant from the National Institutes of Health, Public Health Service. briefing reduces the patient's anxieties and fears to such an extent that he takes the anesthesia better and has less postoperative pain and discomfort. ... And he seems to make speedier recovery from the effects of surgery than the patient who is emotionally unprepared. This is equally true for emotionally normal patients as it is for neurotic patients."

Dyk and Sutherland (2) also stress the surgical patient's need for emotional guidance and rapport with his surgeon. In their study of colostomy patients they found that "anxiety and fear of injury, in some cases mounting to confusion, panic, or despair, were reported by all as reactions to impending surgery."

In another report, concerned with depressive reactions of patients to cancer surgery, Sutherland and Orbach (3), after speaking of anxieties about the nature of the disease, the impending surgery, possible death, or postsurgical social isolation and inacceptability, commented :

"These reactions are particularly prone to occur when the patient is unable to relate to medical personnel. . . . Mistrust is reinforced by the impersonality of clinic and ward procedures and the 'faceless surgeons.' To one depressed patient, surgery represented being cut up by a group of strangers."

Elsewhere, Sutherland (4) wrote: "Apparently prophylaxis is the best treatment. A warm relationship between the patient and the physician is essential. This relationship should permit the doctor to be seen as protective rather than threatening; it should permit easy com- 
munication and discussion of irrational beliefs and misconceptions. . . .

"A good patient-physician relationship, beginning with the initial diagnostic examination, is the patient's best guarantee against the development of crippling beliefs and their expression in unnecessary restriction of activities."

Others have emphasized the surgical patient's need for information and explanation. For example, the widely known standard textbook, Babcock's Principles and Practice of Surgery (5), states:

"Perhaps the best preparation for surgery is for the patient to know his surgeon. Many times contact with the surgeon is so limited that countless questions go unanswered, causing the patient great worry. It is necessary for the surgeon to explain the purpose of the surgery. While this may be quite obvious to him, it is not always obvious to the patient. . . Patients want to know what is to be done and why."

In an essay written in 1928, Cabot (6), referring to the impact of the hospital environment upon the patient, said: "The patient finds himself facing a new and often terrible situation. To enter the hospital is often for him the most momentous event of his life, and he needs all the help that can be given him to understand it."

Although every physician appreciates the importance of a sound physician-patient relationship, and every surgeon knows that his patient is a sentient human being with hopes and fears that affect his attitudes toward treatment, we have found that the interpersonal and communicative aspects of the physician-patient relationship in surgical practice are comparatively too often neglected. Generally, in private surgical practice, the physician is keenly aware of his patient's needs. However, since a substantial number of surgical patients receive care from physicians in surgical residency in government-supported hospitals, gaps may appear between patient needs and surgical practice. In 1954 , an estimated $1,657,550$ surgical patients were discharged from governmentsupported hospitals in the United States (7). Presumably, the resident staff treated the vast majority of these patients as well as an un- determined proportion of some $61 / 2$ million surgically discharged patients in non-government-supported hospitals.

\section{Purpose of Study-}

The teaching hospital is one strategic setting for developing in young physicians a comprehensive approach to medical care centered upon the patient. It is here, as intern and resident, that the young physician may acquire, through intensive instruction and by demonstration, example, and practice many of his most important skills and his basic attitudes about patient care.

In order to examine relationships and attitudes between physician and patient, we undertook an exploratory study of the surgical service of the Bronx Municipal Hospital Center, which is the teaching hospital of the Albert Einstein College of Medicine, Yeshiva University. Most of the patients, house-staff members, and nurses interviewed and observed were on the general surgical service. The study was conducted during the second year of the hospital's existence, a period when the organization of services and activities was formative rather than firmly established. Other relevant background factors were: $(a)$ the medical school with which the hospital is affiliated was also in its second year of existence; students, therefore, had not yet begun serving clinical clerkships; $(b)$ the surgical service was frequently extremely busy, with wards filled to capacity or nearly so; $(c)$ there was an acute shortage and considerable turnover of experienced graduate nurses, practical nurses, and nurse's aides; $(d)$ emergency cases constituted a large percentage of the total work of the surgical service; and $(e)$ the patient population was largely geriatric immigrants of European origin and had language difficulties and environmental handicaps.

\section{Procedures}

Before and after operations, we interviewed 50 surgical patients, unselected except for diagnosis. The selected diagnoses were gastrointestinal, genitourinary, gall bladder, peripheral vascular, respiratory, and skin disorders. Formal interviews were held with a 
sample of the resident surgical staff and graduate nurses on the surgical wards, and informal interviews, of varying length and depth, with a sample of interns serving on the surgical service. We also observed interactions between physicians and patients receiving treatment on the wards, during teaching rounds conducted by the attending surgeons and in the recovery room.

\section{Results}

Some qualitative findings from the study throw light on the question: What are the inherent problems, difficulties, or obstacles in developing total care for surgical patients in a teaching hospital setting? Other findings from this study have been presented in somewhat different contexts $(8,9)$.

Case 1. A 66-year-old retired, unmarried, white woman came to the hospital because she had noticed 2 weeks earlier two small lumps in one of her breasts. When she noticed the lumps, the patient stated, she believed they were due to nervousness, for which she sought relief. In the clinic, the physician said that the lumps were "something serious" and that she should enter the hospital for treatment. At that point, the patient asked if she couldn't go home and return in 2 days, a request made, she admits, for the purpose of avoiding hospitalization. She was dissuaded from this course and admitted to the inpatient surgical service.

Following admission, the surgical staff decided that the patient should have a biopsy and possibly a radical mastectomy. The intern assigned to the case told the patient it was necessary to remove "a little" of the lumps, that then they would probably "go further" with surgery, perhaps removing the entire breast, although they hoped it could be avoided, and that following this surgery, the patient would receive "some treatments." The patient ventured anxiously, "I hope it's not too serious." The physician replied, "No, no. Now you just smile and don't worry." The patient then signed the consent-for-surgery form and the intern left. The patient stated in the preoperative interview that she was nervous and afraid of surgery and recalled postoperative pain from a hemorrhoidectomy some years earlier. She added that it was a shock to her to come to the hospital for relief of nervousness and be hospitalized for surgery.

The surgery consisted of a biopsy and simple mastectomy, followed by radiotherapy.

At postoperative interview, the patient stated that going to the operating room she felt frightened and worried about survival, and regretted she didn't tell her friends goodbye, just in case she didn't return. When she awakened from anesthesia, she knew vaguely that she was "somewhere"; she heard only footsteps and it seemed very quiet. Her first feeling was again of being afraid and wondering if her breast was gone. This question went unanswered until the morning of the first postoperative day, when the intern told her only a small portion of the breast was removed and that she would receive "at least two" radiotherapy treatments. The patient thought she still felt a lump, and the intern explained that what she felt were sutures. The patient told us that she wanted to know what caused her trouble and what she would need to do to care for herself at home but felt "too timid" to ask questions of the doctors.

A few days after the operation the patient received her first radiotherapy. Interviewed the following day, she stated that the experience was very frightening: The sight of instruments on a table in the radiotherapy room made her fearful that further surgery was planned, and the radiotherapy equipment itself, upon being lowered over her, was fear provoking. Nothing the patient could recall indicated that the radiotherapy procedures had been explained to her.

Here we see manifestly an anxious, elderly lady, in whom ignorance concerning cancer or denial of the illness was operating. Proper psychological management of her case required a fuller understanding of her emotional responses to the ominous news of possible major breast surgery and even death. Fear of surgery, concern over removal of a breast, and anxiety about one's death are the most common emotions found in patients with breast disease. If they are not dealt with directly, patients go to and return from surgery with unrelieved apprehensions.

Case 2. A 50-year-old white salesman with 
a long history of diabetes entered the hospital with circulatory insufficiency in the right leg. He was scheduled for a below-knee amputation and subsequent transfer to the rehabilitation service for reambulation and prosthesis.

Prior to admission, the patient had been treated unsuccessfully for almost 1 year at several hospitals. The interview disclosed that the failure of therapies had led the patient to lose considerable confidence in physicians. While on the operating table under spinal anesthesia at another hospital, the patient had been acutely distressed upon hearing the surgeons dispute improper functioning of their equipment. This caused him to feel he was in the hands of incompetent people.

The patient, accustomed to a very active life, was most anxious to learn how long his treatment and rehabilitation would keep him from returning to work. He felt that the year already consumed was "like a lifetime." Five days after the operation, one physician informed the patient that he would go to the rehabilitation service soon, and in "no time at all" he would be up and on his way home. He was also assured that a modern prosthesis is usually easy to fit and to use.

Unfortunately, the patient developed a wound infection which necessitated continued treatment on the surgical ward. He developed a reactive depression and complained vociferously. The intern assigned to the case was annoyed by the patient's temperment and demands, feeling there was nothing he could do for the patient beyond changing his dressings daily.

When the infection cleared and the patient was transferred to the rehabilitation service, he stated that he felt much better because now he was "getting somewhere."

This case reveals the need to counsel the patient who has been through prolonged and varied therapy without positive result so that he may understand the rationale of the planning and maintain his confidence in the medical profession. It points up the consequence of overoptimistic and unqualified statements about the length of treatment and rehabilitation, and the need to apprise the patient realistically of what lies ahead before he can resume his regular activities. As for a patient with major rehabilitation facing him, the doctor's role is by no means confined to the immediate medical treatment. The intern, in this particular case, instead of reacting with a sense of personal annoyance to his patient's anxieties, might have devoted some time to psychological support and viewed his patient's tempermental response as an aspect of the patient's anxiety about the future.

Case 3. A 17-year-old high school girl entered the hospital complaining of dysuria. She was scheduled for cystoscopy 2 days later.

When interviewed, the patient was asked to relate what she believed her trouble was and what the doctors were planning to do for her. In an angry mood, she said: "Dr. L. said they are going to do some kind of examination on me, tomorrow, I think. They say there is something wrong with my kidneys, but they didn't say what. I'd like to know why a young person like me should have kidney trouble, but Dr. L. is always rushing around all the time and I don't get a chance to ask him anything. He doesn't talk to you like a patient." When asked what she meant by the last sentence, the patient said that she had been in another hospital where the doctors explained things to her.

On the day of the scheduled cystoscopy, the interviewer learned that it had been cancelled because the patient's parent had not come to the hospital to give consent for the procedure. The patient had learned that the proposed examination was a cystoscopy, and, having previously had this procedure and finding it painful, prevailed upon her parent not to consent. The patient was discharged to be followed in clinic.

It is evident that in addition to being anxious about a painful diagnostic procedure, the patient wanted the physician to tell her the reason for her illness and the procedure that would be followed. The physician-patient relationship was so undeveloped and communication with the patient was so minimal that the patient acted against medical advice and her own interests. The value of forthright, even if brief, explanation of procedures and planning, presented in a manner that will not alarm the patient, cannot be overestimated. An impersonal attitude toward the patient is one of the contributing factors in the failure of patients to follow medical advice. 
Case 4. A 47-year-old married man was sent to the hospital by his private physician, who had told him that an X-ray showed a shadow on part of one lung and that this might be a tumor. $\mathrm{He}$ was given the same diagnosis by staff physicians in the hospital.

The patient's conception of the intended treatment was "an operation on the part of the lung with the shadow." This was to be done the following day.

Asked if he had questioned the staff physicians about his illness or the planned surgery, the patient said: "Oh, yes. The doctors told me they would like me to ask them about anything that was on my mind. I wondered if the tumor in my lung couldn't be cured by radium. They explained that the best way to be sure I would be cured would be to take the tumor out completely. I believe I really felt a little afraid of an operation on my lung since my family doctor wouldn't even do one on the hernia that I've had a long time. I told the doctors here about this, and they explained to me that this was because the lung problem was more urgent. They assured me that all the tests showed my general health was sound and that I could take the lung surgery without any danger." The patient added that he felt very relieved to have had things cleared in his mind through discussion with the staff physicians, because he had been quite upset when he first learned he required lung surgery.

Interviewed after the operation, the patient related that he felt he was getting fine treatment and singled out the staff surgeon's visits and comments about his progress as making him feel better both physically and mentally. His only problem was wanting to get up and around a little sooner than the surgeon wanted him to.

This case demonstrates as clearly as any studied the value of briefing the patient factually about postoperative events: $\mathrm{He}$ knew that he would awaken in the recovery room, where special care would be given; that he would be expected to cough, and the reason why; that there would be a drainage tube coming out from the operative area; that he would be on a restricted diet for a time; and that he would begin ambulation about 2 days postoperatively.

\section{Discussion}

We introduced the above case studies with a question to which we now return: What are the inherent problems, difficulties, or obstacles in developing total care for surgical patients in a teaching hospital setting? Perhaps the central problem lies in the house officer's definition of his tasks in medical care and the purposes served by the institution. Quite obviously, he is there to learn, and to service hospital patients. Indeed, one may say that his purpose is to learn through serving. In the process of being a physician, he acquires knowledge and skills and extends his experience, which in turn make him a better physician. For the resident, the purpose is to learn to be a surgeon; for the intern, it is to learn more about surgery and care of surgical patients, perhaps as a preliminary to entering surgical residency training, perhaps only as part of general medical training.

The matter becomes somewhat more complex, however, when one goes beyond the obvious functions of the house officer and asks: What, is his conception of his role or task? What does he regard as relevant and significant knowledge to acquire, and what services should he provide? We find, in answer to these questions, that the house officer is more often than not preoccupied with the technical and mechanical aspects of surgery. The desire to communicate with the patient and to develop sound interpersonal relations is regarded as a luxury not expected in nonprivate practice. The ways in which these views are manifested vary from patient to patient and have differing consequences, as the illustrations indicate. In case 4 , where the preparation for surgery was exemplary, the patient went to surgery with minimal anxiety and during postoperative convalescence cooperated fully and cheerfully, because he understood what was necessary and required of him.

\section{Recommendations}

Planning for the development of an improved program for the total care of surgical patients in teaching hospitals must include standards for house staff practice and means of implementing these standards. Standards of practice should incorporate the following: 
1. In addition to the basic physiological preparation of the patient for surgery, attention should be given to psychological factors. During, immediately after, and at regular intervals following admission to the surgical service, the medical staff alone or in conjunction with nursing and social work personnel should evaluate, by physiological and discursive means, the level of and changes in the patient's anxiety about hospitalization and surgery.

2. Hospital rules and regulations and normal procedures of examining, testing, and caring for vital functions should be explained to the patient upon admission and thereafter as indicated.

3. When the time for surgery has been scheduled, the patient should be informed as promptly as possible. Such information should be withheld until the last possible moment only in those instances in which receipt of such information is felt to be detrimental to the patient's general health.

4. In every instance the nature of the operation and the reasons for its being performed should be explained to the patient in terms he is capable of understanding, without necessarily revealing the diagnosis if this is deemed inadvisable (for example, to remove an "obstruction"; to "relieve pressure"). The patient or his family should not be guaranteed by the house officer the successful outcome of surgery.

5. In every instance the choice and type of anesthetic to be used should be explained to the patient by the anesthesiologist on the day of or evening preceding the operation. Whenever possible, such explanation should be given in emergency cases.

6. Preoperative preparation should include explanation of the physical preparation, transportation to the operating room, nature of the operating room, use of the recovery room (in cases where it is used), and length of time that will elapse before return to the ward.

7. Explanation of postoperative pain and other discomforts should be given the patient in advance of surgery.

8. Before the operation, the patient should be prepared for postoperative parenteral alimentation, drainage tubes, dressings, respira- tory activity, range of mobility, and time of ambulation.

9. After the operation it is the surgeon's responbility to discuss the results of surgery, the probable consequences, and the anticipated length of hospitalization and convalescence.

10. The surgeon should discuss the operation and its consequences with the referring physician and responsible members of the patient's family.

The means by which these standards of practice may be implemented are:

1. At the start of the hospital year, the house staff should be oriented through lectures, films, articles, and demonstrations dealing with the total care of surgical patients.

2. At evaluation conferences, house staff members (residents universally and interns where possible) should be given an opportunity to present cases completely worked up from surgical, social, and psychological points of view.

3. Each resident should be given specific instruction and supervision in the psychosocial, presurgical preparation of his patients and in the psychological, postsurgical management of his patients.

4. Teaching rounds should include a psychosocial evaluation of the patient's status and specific coverage of patient responses to the outcome of surgery.

5. Each resident should be instructed and supervised in methods of interviewing the patient and discussing with him and his relatives his problems.

6. Responsible senior surgeons periodically should rate and discuss ratings with residents and interns on the house officer's performance of the psychosocial aspect of his work as well as other aspects.

7. Psychiatrists, social workers, and social scientists should collaborate in these activities designed to improve physician-patient relationships.

\section{Summary}

For the surgeon-in-training, the exigencies of a heavy work schedule, large patient load, and necessity of mastering the specialized knowledge and techniques of an increasingly com- 
plex field leave little opportunity for him to become versed in the recognition and management of a patient's psychosocial needs. Such needs are recognized in surgical literature and by experienced practitioners and teachers of surgery, but they are often inadequately met. Standards of practice as well as steps to implement them are outlined, so that ideal surgical practice with respect to these needs may be approximated in the teaching hospital.

\section{REFERENCES}

(1) Kaufman, W.: The physician's role in the preparation of a patient for surgery. In Psychosomatic aspects of surgery, edited by $A$. J. Cantor and A. N. Foxe. New York, Grune and Stratton, 1956, pp. 1-2.

(2) Dyk, R. B., and Sutherland, A. M.: Adaptation of the spouse and other family members to the colostomy patient. Cancer 9: 124, JanuaryFebruary 1956.

(3) Sutherland, A. M., and Orbach, C. E. : Psychologi- cal impact of cancer and cancer surgery. II. Depressive reactions associated with surgery for cancer. Cancer 6: 959, September 1953.

(4) Sutherland, A. M.: Psychologic barriers to rehabilitation of cancer patients. Postgrad. Med. 17 : 526, June 1955.

(5) Babcock, W. W.: Principles and practice of surgery, edited by $\mathrm{K}$. C. Jonas. Philadelphia, Lea and Febiger, 1954, p. 1496.

(6) Cabot, R. C. : Hospital and dispensary social work (excerpt). In Expanding horizons in medical social work, edited by D. Goldstine. Chicago, University of Chicago Press, 1955, p. 262.

(7) Dickinson, F. G., and Raymond, J.: Some categories of patients treated by physicians in hospitals. American Medical Association, Bureau of Medical Economic Research, Bull. 102 and 102A. Chicago, 1956, table 9, p. 16.

(8) Brant, C., and Kutner, B.: Physician-patient relations in a teaching hospital: Some implications for medical education. J. Med. Educ. 32 : 703-707, October 1957.

(9) Brant, C., and Kutner, B.: Interpersonal relationships and comprehensive surgical care. The New Physician 7 : 23-25, 95, April 1958.

\section{Textbook on Medical Care Organization}

More than a hundred articles on the organization of medical care are brought together in the recently published textbook entitled "Readings in Medical Care," edited by the Committee on Medical Care Teaching of the Association of Teachers of Preventive Medicine.

The book contains basic studies dating back to the 1920's as well as important recent ones in books, journals, and monographs, together with extensive reading lists. Several articles appeared in Public Health Reports and other government publications, and many are the work of Government employees or former employees, printed elsewhere.

Prepared in response to a widely felt and frequently expressed need for teaching material, the new textbook grew out of a conference on preventive medicine in medical schools held in Colorado Springs in November 1952. This conference was sponsored by the Association of Teachers of Preventive Medicine and the Association of American Medical Colleges.

"Subsequent to that searching exploration of the growing importance of preventive medicine in medical education," Dr. George Packer Berry, of Harvard University, says in the foreword, "the Committee ... have devoted their efforts to understanding, evaluating, and recording changes in the patterns of organization of medical care and health service." 


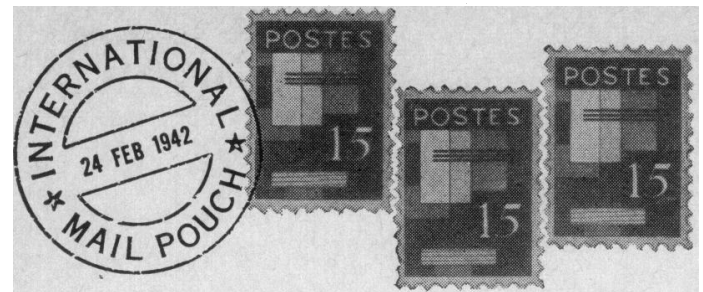

Korean Texts

Nurses in Korea will soon have five Korean texts to aid them. The medical care bureau of the Republic of Korea's Ministry of Health and Social Affairs recently issued Basic Nursing Methods and Nursing Care of Pregnant Women, and the Korean Nurses Association has ready for publication two other texts, Medical Nursing and Nursing Care of Children. The Korean Red Cross is planning to publish Home Nursing, which will be a useful reference for public health nurses, home economics teachers, and other professional workers as well as individual families.

-Alfred S. Lazarus, Ph.D., acting chief, Health and Sanitation Division, U.S. Operations Mission, Korea.

\section{Pipeline}

In one day, 100 villagers of Sapum, Thailand, built a pipeline to bring water to their small community from the nearest source, a hillside spring half a kilometer away. After several outlets were installed in the village, the people decided to build a storage tank at the spring and additional branch lines from the main distribution line to more remote parts of the village.

The people volunteered their labor, and the local health department provided the materials for the distribution system.

-Robert L. Zober, M.D., chief, Health Division, U. S. Operations Mission, Thailand.

\section{Male Nurses}

When the 17 men who started courses in February 1958 at the School of Nursing, Tubman National Institute of Medical Arts, Monrovia, are graduated, this profession may gain new status in Liberia.

Six men and twelve women are taking the 3-year course in professional nursing, and 11 men and 3 women are in the 2-year course for practical nurses.
The 8 students who will study midwifery for 2 years are women. These candidates for the school were selected from a much larger group by written examinations, given in many of the smaller towns as well as the capital, and personal interviews.

Only five of the students come from Monrovia; most are from much smaller towns and the rural areas. Eight are high school graduates, 13 have attended high school, and 15 completed the eighth grade. Their ages range from 16 to 34 years, with 23 as the average age in the professional nursing and midwifery courses and 22 in the practical nursing course.

The students listed their fathers' occupations on application blanks. Most of their fathers are farmers or fishermen, a few are teachers, and three are tribal chieftains.

-James P. Ward, M.D., chief, Public Health Division, U. S. Operations Mission, Liberia.

\section{Sick Students}

Fifty candidates came to take the entrance examinations at Itegue Menen School of Nursing in Asmara, Ethiopia. Of the 26 accepted after examination, it was necessary to treat 12 for trachoma, 14 for amebiasis, 2 for congenital syphilis, and 1 for ascariasis.

-A. C. Curtis, M.D., chief, Public Health Program, U.S.Operations Mission, Ethiopia.

\section{Occupational Health in Peru}

The Peruvian National Association on Occupational Health was formed after Peru's first national seminar in this field was held in January 1958. The medical directors and safety engineers of many industrial and mining companies in Peru as well as private physicians, nurses, and public health workers were among the 94 persons attending.

The seminar participants included faculty mem. bers from Harvard University, Marquette University, Peru's National University of Engineers, and San Marcos School of Medicine, the Peruvian and the United States consultants in industrial hygiene, and representatives from Brazil, Colombia, Bolivia, and Venezuela.

-Frederick J. Vintinner, Sc.D., M.P.H., chief, Division of Health and Sanitation, U. S. Operations Mission, Peru. 


\section{Transfer in San Martín}

After 11 years of work by Servicio Cooperativo Interamericano de Salud Pública in San Martín Department, in January 1958 we turned over the health unit to Peru's Ministry of Health. Since 1946 SCISP has gradually developed public health and medical care services for the 400,000 people living in this high, jungle area.

The health unit for San Martín consists of a 50bed hospital and health center in Tarapoto, a health center in Moyobamba, medical posts in Lamas, Rioja, Juanjui, and Saposoa, and 15 health posts in the smaller towns. In accepting responsibility for the health service, the government of Peru assumed a yearly financial obligation of approximately $\$ 130,000$, or 3.5 million soles.

-Frederick J. Vintinner, Sc.D., M.P.H., chief, Division of Health and Sanitation, U. S. Operations Mission, Peru.

\section{The Road Back}

The small government hospital in Voinjama, district and provincial headquarters of Liberia's Western Province, is the center of a proposed project to combat sleeping sickness. Because the trucks that brought supplies to the hospital often took a week to get there from Monrovia, the capital, and this transportation cost $\$ 350$, I decided to investigate the logistics of providing services to Voinjama myself.

I made the 200-mile trip to Voinjama in 2 hours in a light plane, but returning to Monrovia in a 4-wheel drive jeep took far longer. The road back goes through French Guinea so visas and re-entry permits had to be arranged. The first leg of the jeep journey ended at Macenta, 36 miles and 4 hours from Voinjama. We were told we had made excellent time; frequent rains turn the laterite of the roads into mud paste, but our jeep was stuck only once, in front of the French customs station.

On this trip I developed an essential skill, bridge building. The ordinary ones are made of logs placed lengthwise across streams. Frequently the wheels of a truck force the logs apart and the truck tumbles into the stream or its axles are suspended on the logs.

After stopping overnight in Macenta, we left early the next morning for N'Zérékoré, still in French Guinea. On the way we crossed the St. Paul River.
Vehicles are ferried across its 100 yards on a handpulled barge, but travelers on foot use the famous "monkey bridge," constructed entirely of long vines twisted together to make two handrails connected by a sling. I stepped gingerly across the swaying span which tightens and dips at each step but ingeniously serves its purpose, except when rotting vines are not replaced.

We reached N'Zérékoré, the second overnight stop, after driving the 61 miles in 7 hours. Next morning we drove to Ganta on the Liberian side of the border and made the final leg of the journey to Monrovia in about 8 hours.

When the new road is completed, getting supplies to Voinjama will not be so difficult, and air service to the town may soon be started by Liberian National Airways.

- JAMES P. WARD, M.D., chief public health and sanitation division, $U$. S. Operations Mission, Liberia.

\section{The Spring}

Rurrenabaque, a little town in the jungle uplands of Bolivia, was not far from a clear spring at the base of a cliff which could amply serve 5,000 people. The spring was high enough to feed the town by gravity flow. But the people could scarcely reach the spring on foot and Servicio engineers faced formidable obstacles to bring the water to the town in channels.

No road from La Paz, 150 miles distant, led to Rurrenabaque. Planes ferried in most of the equipment and materials needed to convert the spring into an accessible water supply. The dynamite for blasting came part of the way by truck and then by mule pack and canoe to the remote site.

No machines of any size could be used at the spring itself. Drilling for blasting operations had to be done by hand. The piers, heavy pieces of timber 25 feet long and each weighing more than a ton, had to be carried by men through the tropical forest. A human chain passed along the stones for the foundations of the piers.

After more than a year of such labor by the townspeople, the fresh, clear water of the mountain spring flowed into Rurrenabaque.

-Harald S. Frederiksen, M.D., chief, health and sanitation division, U. S. Operations Mission, Bolivia. 